\title{
Schistosomal Myeloradiculopathy due to Schistosoma mansoni: Report on 23 Cases
}

\author{
Vandack Nobre, Luciana CS Silva, João G Ribas*, Abdunnabi Rayes, JC Serufo, \\ MA Lana-Peixoto, Rosana FZ Marinho, JR Lambertucci ${ }^{+}$
}

\begin{abstract}
Faculdade de Medicina, Universidade Federal de Minas Gerais, Av. Alfredo Balena 190, 30130-100 Belo Horizonte, MG, Brasil *Hospital Sarah Kubistchek/Associação das Pioneiras Sociais, Belo Horizonte, MG, Brasil

Schistosoma mansoni infection is likely to be responsible for a significant proportion of cases of myelopathy occurring in areas where schistosomiasis is endemic. The aim of this study is to describe the clinical, laboratory and therapeutic data of 23 patients with schistosomal myeloradiculopathy. The medical records of 23 patients with schistosomal myelopathy admitted to two general hospitals of Belo Horizonte (MG), in Brazil, from 1995 to 1999, were reviewed retrospectively. Seventeen patients were male (74\%). The mean age for the whole group was 27 years. Lower limb weakness and associated lumbar and/or lower limb pain were reported by 20 patients (87\%), and $16(70 \%)$ were unable to walk. All individuals presented urinary retention and 19 (83\%) complained of intestinal dysfunction. The treatment was based on the association of antischistosomal drugs and corticosteroids. Five patients (22\%) presented a full response to treatment, $13(57 \%)$ partial response without functional limitations and $4(17 \%)$ partial improvement with limitations or no response. Three out of the 4 patients who stopped steroids before 45 days of treatment developed recurrence of the symptoms and signs of myelopathy. Our cases demonstrate the severe presentation of the disease and the data disclosed here suggest that treatment with steroids should be kept for months after clinical improvement.
\end{abstract}

Key words: schistosomiasis - myelopathy - neuroschistosomiasis - myeloradiculopathy

Spinal cord schistosomiasis is the most severe ectopic form of schistosomal infection. In 1905, Shimamura and Tsunoda demonstrated for the first time the presence of lumbar spinal cord schistosomiasis in a patient with transverse myelitis, produced by Schistosoma japonicum (apud Faust 1947). S. mansoni is most frequently associated to myeloradiculopathy worldwide. S. mansoni eggs were first identified in the spinal cord of a patient who lived in Brazil by Müller and Stender (1930). In Brazil, 3 to 4 million people are infected and 30 million are exposed to this infection (Amaral \& Porto 1994).

The pathogeny of schistosomal myeloradiculopathy is not clearly understood, but there is convincing evidence that central nervous system lesions depend on the host inflammatory response to the eggs layed in the nervous tissue (Pitella 1997). Interestingly, schistosomal myeloradiculopathy is more frequently associated with the intestinal and hepatointestinal chronic forms of schistosomiasis (Pittella et al. 1996).

Work partially supported by CNPq-Brasil.

E-mail: lamber@ net.em.com.br

Received 14 May 2001

Accepted 25 July 2001
The diagnosis of this disease is based on evidence of low thoracic/upper lumbar neurologic symptoms, demonstration of schistosomal infection by microscopic or serologic techniques, and exclusion of other causes of transverse myelitis (CDC 1984).

Therapeutic options for schistosomal myeloradiculopathy are antischistosomal drugs and corticosteroids, and surgery is rarely indicated. There is no consensus about doses and duration of treatment (Cosnett \& Van Dellen 1986, Haribhai et al. 1991, Ueki et al. 1995, Ferrari 1999, Lambertucci et al. 2000). The sooner the treatment is started, the better. If left untreated, most patients die or do not show any improvement (Peregrino et al. 1988, Haribhai et al. 1991).

The prevalence of schistosomal myeloradiculopathy is unknown. Some authors have expressed the opinion that this disease has been underestimated and underdiagnosed (Joubert et al. 1990, Lambertucci 1993, Ferrari 1999).

We describe here the clinical, laboratory and therapeutic data of 23 patients with schistosomal myeloradiculopathy evaluated in Belo Horizonte, Minas Gerais, Brazil, in a period of five years.

\section{PATIENTS AND METHODS}

The medical records of 23 patients with myelopathy admitted to two general hospitals of Belo 
Horizonte from 1995 to 1999 were reviewed retrospectively. The information obtained, such as demographic (i.e. age, gender and procedence), clinical (i.e. mainly clinical manifestations) and laboratory data were stored in a computer data bank using the Epi Info 6.04b software.

Seventeen patients were male $(74 \%)$. The age ranged from 4 to 54 years (mean $\pm \mathrm{SD}, 27 \pm 13.8 \mathrm{yr}$; median, $24 \mathrm{yr}$ ). A history of contact with natural waters was present in all cases.

Schistosomal myeloradiculopathy was defined according to the following criteria: evidence of low spinal cord lesion, demonstration of exposure to schistosomal infection by microscopic techniques and exclusion of other causes of transverse myelitis. The level of medullar lesion was defined by the sensory level detected at the neurological examination.

All patients had a microscopic demonstration of schistosomal eggs in stool examination (Hoffman-Pons-Janer method) or rectal biopsy. Biochemistry and cytomorphologic examination of the cerebrospinal fluid obtained by lumbar puncture were performed in $12(52 \%)$ patients.

Seventeen patients were submitted to radiologic examination and the following techniques were used: myelography, computed tomography (CT) with myelography and magnetic resonance imaging (MRI) in the medical institutions where they were admitted for treatment.

All individuals were treated with schistosomicides; they received either oxamniquine (15$20 \mathrm{mg} / \mathrm{kg}$, body weight, single dose), or praziquantel ( $50 \mathrm{mg} / \mathrm{kg}$, body weight, single dose).

Steroids were started thereafter (prednisone, 1$2 \mathrm{mg} / \mathrm{kg} /$ body weight) and maintained for a period which varied from 40 days to 12 months. Six patients received methylprednisolone (1 gram/day for 5 days), as pulse therapy, before starting treatment with prednisone.

The initial and subsequent neurological evaluations of the patients were also performed by a neurologist. As this was not a prospective study, patients were attended by different physicians. Therapeutic response was defined as: (1) full recovery when the patient presented complete improvement of his neurological status; (2) partial recovery without functional limitations when the patient remained with only minor deficits that did not interfere with daily activities; (3) partial recovery with limitations or no recovery if the patient did not show any improvement or was left with permanent disabling weakness or sensory loss.

\section{RESULTS}

Clinical manifestations - Paresthesia in lower limbs and lumbar and/or lower limb pain were the most frequent early clinical manifestations, occurring respectively in $43 \%$ and $29 \%$ of the patients. The frequency of the major clinical manifestations are listed in Table I.

The level of spinal cord lesion was defined by neurologic examination with delimitation of the sensory level. The thoracolumbar region was most frequently involved (91.3\%).

The search for $S$. mansoni eggs in the stool was performed in 11 patients. A positive result was found in $4(36 \%)$. In the remaining 19 patients the eggs were detected by rectal biopsy.

The examination of the cerebrospinal fluid of 12 patients showed a nonspecific inflammatory pattern, with a rise in protein $(76.5 \mathrm{mg} \% \pm 66.5 \mathrm{mg} \%)$ and cell count $\left(53.3\right.$ cells $/ \mathrm{mm}^{3} \pm 40.4$ cells $/ \mathrm{mm}^{3}$ ). There was a predominance of lymphocytes; eosinophils were detected in 5 samples (42\%). Glucose levels were always unchanged.

Eosinophil counts of more than 400 cells $/ \mathrm{mm}^{3}$ were found in the peripheral blood of only $7 \mathrm{pa}-$ tients $(30 \%)$.

Six patients were submitted to contrasted radiologic methods (myelography or CT-myelography), 4 of them with negative results. The two patients with alterations showed filling defects due to expansion of the spinal cord. Eleven patients (48\%) were submitted to MRI. All but one had alterations. In general, the most frequent findings were localized enlargement of the spinal cord, alterations in the intensity of the signal and contrast enhancement after gadolinium injection.

The therapeutic approach was based on the association of an antischistosomal drug and corticosteroids. The former was used by all patients and $20(87 \%)$ were also treated with corticosteroids (prednisone, mean initial dose of $66.7 \mathrm{mg} /$ day). Six patients received pulse therapy with methylprednisolone ( $1 \mathrm{~g} / \mathrm{day}$ for 5-6 days). In 10 patients steroids were used for a mean of 5.4 months.

In general, the outcome of the patients was good (Table II). Five (21.7\%) presented a full re-

\section{TABLE I}

Major neurologic findings in 23 patients with schistosomal myeloradiculopathy in a 5 years period

(1995-1999) in two general hospitals of Belo Horizonte (MG), Brazil

\begin{tabular}{ll}
\hline Neurologic findings & $\mathrm{n}(\%)$ \\
\hline Bladder dysfunction & $23(100)$ \\
Lower limb muscles weakness & $20(87)$ \\
Unable to walk & $16(70)$ \\
Lumbar and /or lower limbs pain & $20(87)$ \\
Intestinal dysfunction & $19(83)$ \\
Paresthesia & $22(95.6)$
\end{tabular}


TABLE II

Therapeutic response presented by 22 patients with schistosomal myeloradiculopathy in a 5 years period (1995-1999) in two general hospitals of Belo Horizonte (MG), Brazil

\begin{tabular}{ll}
\hline Response & $\mathrm{n}(\%)$ \\
\hline Full recovery & $5(21.7)$ \\
Partial recovery without limitation & $13(56.5)$ \\
$\begin{array}{l}\text { Partial recovery with limitations } \\
\text { or no recovery }\end{array}$ & $4(17.4)$ \\
\hline
\end{tabular}

sponse to treatment, $13(56.5 \%)$ a partial response without functional limitations and $4(17.4 \%)$ a partial recovery with limitations or no response. In one patient this information was not available. Ten out of the 13 patients with a partial response still showed continuous improvement of their clinical status on the occasion of this study.

To illustrate the clinical presentation, the morbidity of neurologic involvement and the therapeutic outcome of a patient with schistosomal myeloradiculopathy the history of one of our patients is summarized below.

Case report - A 23 years old man started with a subtle picture of paresthesia in the lower limbs followed by a burning low-back pain. Three days later he complained of paraparesis that progressed to paraplegia in one week. There was no sphincter involvement. He was admitted to hospital and the diagnosis of schistosomal myeloradiculopathy was suspected since he lived in an area endemic for schistosomiasis. No parasites were found in stool examination but a rectal biopsy showed viable ova of S. mansoni. Oxamniquine (1000 mg, total dose) and dexametasone ( $16 \mathrm{mg} /$ day $)$ were started without delay. Steroids were discontinued seven days after its initiation. Notwithstanding, there was a progressive improvement of signs and symptoms. One month later, however, he noticed recurrence of the previous signs and symptoms associated with fecal and urinary retention. He was admitted to our university hospital after thirteen days. The general physical examination was normal but the neurologic evaluation showed an important decrease in strength ( 2 on a scale of 5 ) of lower limbs preventing the patient from walking. Absence of lower limbs deep tendon reflexes and hypoesthesia at the level of T10 were detected. The cerebrospinal fluid revealed 45 white cells $/ \mathrm{mm}^{3}$ ( $100 \%$ of lymphocytes), $67.3 \mathrm{mg} / \mathrm{dL}$ of protein and $57 \mathrm{mg} / \mathrm{dL}$ of glucose. Eosinophils were not reported. There were no alterations on CT-myelography. The MRI showed a widening of the spinal cord from T9 to L2 and contrast enhancement on T1-weighted images after gadolinium administration (Figure). The patient was

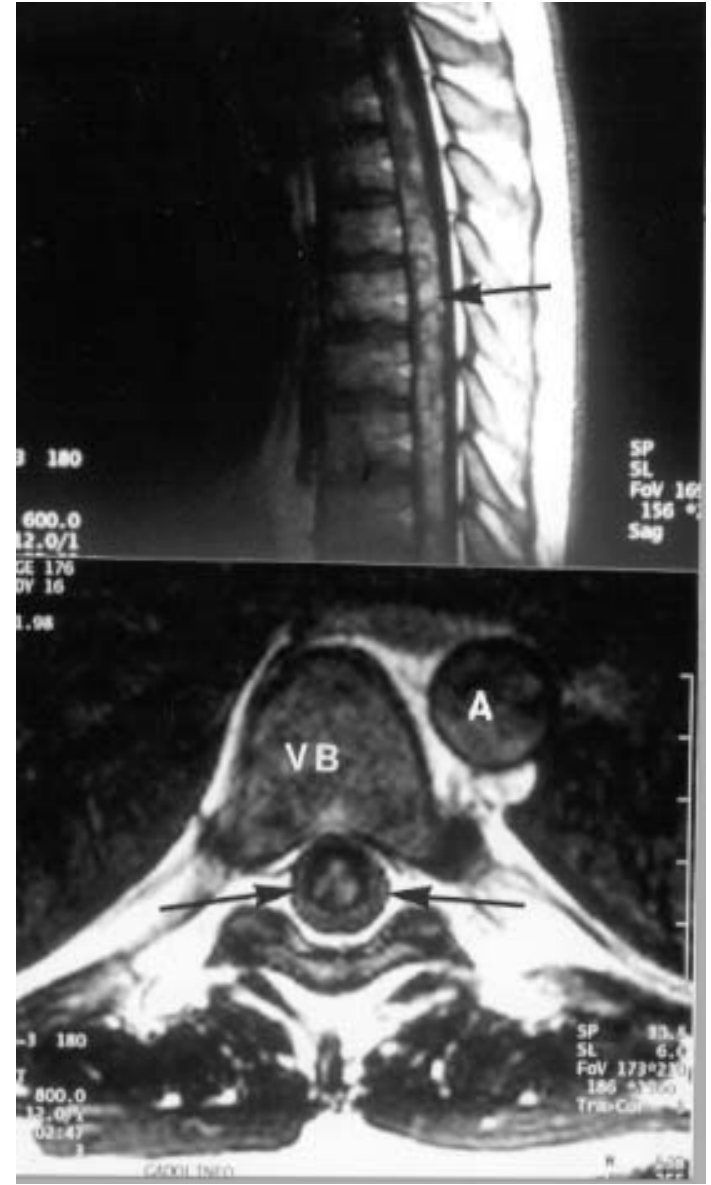

A T1-weighted gadolinium-enhanced magnetic resonance imaging (MRI) of the spinal cord of a patient with schistosomal myeloradiculopathy. Notice the granular aspect of the medullar lesion (spotty enhancement). Arrows are pointing to white areas - revealed by the uptake of the gadolinium contrast - that are affected by the disease. A: aorta; VB: vertebral body. A sagittal (upper part of the figure) and a cross-sectional (lower part of the figure) view of the spinal cord.

submitted to pulse therapy with methylprednisolone ( $1 \mathrm{~g} /$ day for 5 days) followed by prednisone ( 2 $\mathrm{mg} / \mathrm{kg} /$ day). Physiotherapy and psychological assistance were offered. The clinical picture improved and the patient was discharged from hospital 36 days after admission. Steroids were tappered off progressively and maintained for 12 months. The patient remains well at follow-up 24 months after dismissal.

\section{DISCUSSION}

The clinical and therapeutic aspects of 23 patients with myelopathy due to $S$. mansoni are here described. There was a predominance of male and this can be partially explained by their greater exposure to schistosomal infection. Some authors 
hypothesize that differences in pelvic anatomy could be responsible for this gender difference (Scringeour \& Gajdusek 1985).

It should be emphasized how severe can be the presentation of schistosomal myeloradiculopathy. Most individuals (70\%) were unable to walk. Information regarding the early clinical symptoms showed that paresthesia in lower limbs outpace lumbar and/or lower limbs pain as the initial clinical manifestation.

Traditionally the SMR has been characterized in three clinical forms: transverse myelitis, granulomatous and myeloradicular (Bird 1964). An additional and uncommon vascular pattern, resulting from the occlusion of the spinal artery or of its branches has been described (Silbergleit et al. 1992). In our experience the division of schistosomal myeloradiculopathy in clinical forms is extremely difficult. The incorporation of new technologies such as the MRI associated with the progressive knowledge acquired about this entity will permit a more reliable and accurate classification.

Only a few patients were submitted to contrasted imaging, most of them with negative results. However all 11 but one individual in whom a MRI was performed showed alterations. There is a limited experience in the literature with the study of schistosomal myeloradiculopathy by MRI (Masson et al. 1990, Dupuis et al. 1990, Selwa et al. 1991, Silbergleit et al. 1992, Blunt et al. 1993). Despite that the findings suggest that it is much more sensitive than myelography and CT-myelography in the diagnosis of this condition. We are routinely performing MRI in patients with suspected schistosomal myeloradiculopathy.

Our patients were not submitted to immunotests. The finding of antibodies against $S$. mansoni can be used as a criterium for schistosomal myeloradiculopathy diagnosis (CDC 1984). Some investigators have stated that the presence of cerebrospinal fluid anti-Schistosoma antibodies (mainly using ELISA and immunofluorescence) is a reliable sign of intrathecal schistosomal infection (Peregrino et al. 1988, Dupuis et al. 1990). However, it may just represent a past exposure to the worm (Lambertucci et al. 2000).

A definite diagnosis of schistosomal myeloradiculopathy requires histologic examination of the spinal cord. Taking into account the recent propedeutic and therapeutic advances, biopsy of the spinal cord has been used less frequently lately. Therefore, in our study, except for one patient, the diagnosis was presumptive and based on a suggestive clinical picture, demonstration of exposure to schistosomal infection and exclusion of other causes of spinal cord damage.
There are no controlled randomized trials comparing different treatments for schistosomal myeloradiculopathy. However, an analysis of the literature shows that the association of corticosteroids and antischistosomal drugs is related to the best outcome (Galvão 1983). The doses and the duration of treatment with steroids are still subject of discussion. In our series 3 out of the 4 patients who stopped steroids before 45 days of treatment presented recurrence of the symptoms and signs of myelopathy. In addition, we have observed that clinical improvement may occur late in the course of the disease with the maintenance of steroid therapy.

The appropriate treatment of schistosomal myeloradiculopathy should be multiprofessional involving the participation of physiotherapists, nurses, psychologists, clinicians and neurologists. The occurrence of urinary tract infection is common and bed sores should be strongly avoided.

Schistosomal myeloradiculopathy does not appear to be a rare ectopic manifestation of $S$. mansoni infection. The disease has probably been underdiagnosed and reports in the literature represent only the tip of the iceberg. According to that, schistosomal myeloradiculopathy should be always taken into account when one is evaluating morbidity in endemic areas for schistosomiasis. As stated before an early and adequate treatment is usually related to a surpassing outcome. All patients living in endemic areas or with a history of schistosomal exposure and evidence of myeloradiculopathy should be treated promptly. Meanwhile, extra efforts should carry on to establish a definite diagnosis of the cause of the myelopathy. Contraindications to steroids must be considered but will rarely prevent this drug from being used.

\section{REFERENCES}

Amaral RS, Porto MAS 1994. Evolução e situação atual do controle da esquistossomose no Brasil. Rev Soc Bras Med Trop 27 (Supl. III): 73-90.

Bird AV 1964. Acute spinal schistosomiasis. Neurology 14: 647-656.

Blunt SB, Boulton J, Wise R 1993. MRI in schistosomiasis of conus medullaris and lumbar spinal cord [Letter]. Lancet 341: 557.

Centers for Disease Control and Prevention 1984. Acute schistosomiasis with tranverse myelitis in American students returning from Kenia [editorial note]. Morb Mortal Wkly Rep 33: 446-447.

Cosnett JE, Van Dellen JR 1986. Schistosomiasis (bilharzia) of the spinal cord: Case reports and clinical profile. Q J Med 61: 1131-1139.

Dupuis MJM, Atrouni S, Dooms GC, Gonrette RE 1990. MR imaging of schistosomal myelitis. Am J Neuroradiol 11: 782-783.

Faust EC 1947. An inquiry into the ectopic lesions in 
schistosomiasis. 43rd Annual Meeting, Am Soc Trop Med, Atlanta, Georgia, December 4.

Ferrari TCA 1999. Spinal cord schistosomiasis: a report of 2 cases and review emphasizing clinical aspects. Medicine 78: 176-190.

Galvão ACR 1983. Mielopatias Esquistossomóticas: Aspectos Clínicos e Laboratoriais. Thesis. Universidade de São Paulo, São Paulo.

Haribhai HC, Bhigjee AI, Bill PLA, Pammenter MD, Modi G, Hoffmann M, Kelbe C, Becker P 1991. Spinal cord schistosomiasis: a clinical, laboratory and radiologic study, with a note on therapeutic aspects. Brain 114: 709-726.

Joubert J, Fripp PJ, Hay IT, Davel GH, Van Graan ESJ 1990. Schistosomiasis of the spinal cord underdiagnosed in South Africa? South Africa Med J 77: 297-299.

Lambertucci JR 1993. Schistosoma mansoni: pathological and clinical aspects. In P Jordan, G Webbe, RF Sturrock (eds), Human Schistosomiasis, Cab International, Wallingford, p. 195-225.

Lambertucci JR, Serufo JC, Gerspacher-Lara R, Rayes AAM, Teixeira R, Nobre V, Antunes CMF 2000. Schistosoma mansoni: assessment of morbidity before and after control. Acta Trop 77: 101-109.

Masson C, Rey A, Ast G, Cambies J, Masson M 1990. Schistosomiase medulaire: apport de 1' imagine par resonance magnetique. Presse Med 19: 1223-1224.

Müller HR, Stender A 1930. Bilharziose des
Rückenmarkes unter dem Bilde einer myelitis dorsolumbalis transversa completa. Arch $f$ Schiffs $-U$ Tropen-Hyg 34: 527-538.

Peregrino AJP, Oliveira SP, Porto CA, Santos LA, Menezes EE, Silva AP, Brito AL, Pinheiro SP, Pinheiro S, Dias AB 1988. Meningomielorradiculite por Schistosoma mansoni: Protocolo de investigação e registro de 21 casos. Arq Neuropsiq 46: 49-60.

Pittella JEH, Gusmão SN, Carvalho GT, Silveira RL, Campos GL 1996. Tumoral form of cerebral schistosomiasis mansoni: a report of four cases and a review of the literature. Clinic Neurol Neurosur 98: 15-20.

Pittella JEH 1997. Neuroschistosomiasis. Brain Pathol 7: 649-662.

Scrimgeour R, Gajdusek DC 1985. Involvement of the central nervous system in Schistosoma mansoni and S. haematobium infection: a review. Brain 108: 10231038.

Selwa LM, Brunberg JA, Mandell SH, Garofalo EA 1991. Spinal cord schistosomiasis: a pediatric case mimicking intrinsic cord neoplasm. Neurology 41: 755-757.

Silbergleit R, Silbergleit R 1992. Schistosomal granuloma of the spinal cord: evaluation with MR imaging and intraoperative sonography. Am J Roentgenol 158: 1351-1353.

Ueki K, Parisi JE, Onofrio BM 1995. Schistosoma mansoni infection involving the spinal cord: case report. J Neurossur 82: 1065-1067. 
142 Schistosomal Myeloradiculopathy • Vandack Nobre et al. 